\begin{tabular}{|c|c|c|}
\hline \multirow{3}{*}{$\begin{array}{r}\text { Case Reports in } \\
\text { Gastroenterology }\end{array}$} & \multirow{2}{*}{\multicolumn{2}{|c|}{ Case Rep Gastroenterol 2014;8:7-12 }} \\
\hline & & \\
\hline & $\begin{array}{l}\text { DOI: } 10.1159 / 000358045 \\
\text { Publisned onlme: January 9, } 2014\end{array}$ & $\begin{array}{l}\text { (c) } 2014 \text { S. Karger AG, Basel } \\
\text { 1662-0631/14/0081-0007\$39.50/0 } \\
\text { www.karger.com/crg }\end{array}$ \\
\hline & \multicolumn{2}{|c|}{$\begin{array}{l}\text { This is an Open Access article licensed under the terms of the Creative Commons } \\
\text { Attribution-NonCommercial } 3.0 \text { Unported license (CC BY-NC) (www.karger.com/OA- } \\
\text { license), applicable to the online version of the article only. Distribution permitted for non- } \\
\text { commercial purposes only. }\end{array}$} \\
\hline
\end{tabular}

\title{
Intestinal Neuronal Dysplasia Type B in Adults: A Controversial Entity
}

\author{
Vasillis Vougas $^{\mathrm{a}} \quad$ Konstantinos Vardas $^{\mathrm{a}}$ Christos Christou $^{\mathrm{a}}$ \\ Georgios Papadimitriou $^{a}$ Evangelia Florou $^{a}$ Christina Magkou $^{b}$ \\ Dimitrios Karamanolis $^{c}$ Dimitrios Manganas ${ }^{a}$ Spiros Drakopoulos ${ }^{a}$ \\ ${ }^{a}$ First Department of Surgery and Transplant Unit, ${ }^{b}$ Department of Pathology and \\ ${ }^{\mathrm{C}}$ Department of Gastroenterology, Evangelismos General Hospital, Athens, Greece
}

\section{Key Words}

Chronic constipation · Hyperganglionosis · Intestinal neuronal dysplasia

\begin{abstract}
Intestinal neuronal dysplasia (IND) is a well-defined entity which raises controversy among authors, described as a congenital malformation of gastrointestinal innervation and caused by dysplastic embryonal development of the enteric nervous system. It is potentially associated with mild and chronic gastrointestinal motility disturbances. IND is rarely reported in adults and especially elderly patients. The present study reports on the case of a 71-year-old man suffering from longstanding idiopathic constipation and who was misdiagnosed for more than 60 years, despite several hospital admissions and a sigmoidectomy in the meantime. On the last admission, the patient presented with megacolon, abdominal pain and $\mathrm{X}$-ray finding of bowel obstruction. Due to massive large bowel dilatation, an exploratory laparotomy failed to reveal any obvious mechanical cause, and a subtotal colectomy and Hartmann's procedure was performed. Bowel continuity was performed 3 months later. Analysis of full-thickness biopsies revealed enlarged myenteric and submucosal neurons as well as an increased number of giant cells and increased acetylcholinesterase activity in the mucosa. The diagnosis of IND was established. The main diagnostic criteria, the underlining pathophysiology and the recommended therapeutic approach of this rare entity are extensively reviewed.

(c) 2014 S. Karger AG, Basel
\end{abstract}


Vougas et al.: Intestinal Neuronal Dysplasia Type B in Adults: A Controversial Entity

\section{Introduction}

The morphological features of intestinal neuronal dysplasia (IND) type B were first described in 1970 by Nezelof et al. [1]. One year later, Meier-Ruge [2] further clarified the condition, naming it neuronic dysplasia of the colon. Nowadays, IND is a well-defined entity which raises controversy among authors, defined as a congenital malformation of gastrointestinal innervation and characterized by specific histopathologic features [3]. It usually presents in childhood and there are only a few reports in adults, which have implicated IND type B as a cause of pseudo-obstruction, chronic constipation and diverticulosis of the colon [4]. Due to rarity of IND in adults and especially in elderly patients it can be easily misdiagnosed. The present case illustrates the result of longstanding idiopathic constipation, which remained without proper treatment for more than 60 years despite several hospital admissions and a sigmoidectomy in the meantime.

\section{Case Report}

A 71-year-old male patient presented to the surgical emergency department of our hospital complaining of abdominal pain and constipation. Basic laboratory tests on admission were within normal range. Clinical examination revealed abdominal distention, dehydration and no evidence of bowel sounds. Systemic and neurologic diseases as well as infections and malabsorption syndromes were excluded by medical history, physical and blood examination. From the patient's history, chronic constipation had achieved 20 points in the Wexner Constipation Scale (WCS) [5] since his infancy. He had occasionally received treatment with laxatives and rectal enemas. His last surgery had been 10 years before and included sigmoidectomy. Histopathology analysis of the resected sigmoid colon showed a dilated bowel with no evidence of malignancy, and no other immunohistological analysis was done. The patient stated that the symptoms of constipation had never resolved, while during the last 6 months he had been admitted to hospital twice due to bowel obstruction and treated without surgery.

During the last admission to our hospital, an abdominal X-ray showed a massively distended large bowel (fig. 1), and an abdominal computed tomography scan did not reveal any mechanical obstruction (fig. 2). Due to excess abdominal tenderness and radiological findings, it was decided that an exploratory laparotomy would be appropriate. During laparotomy (fig. 3) no obvious mechanical cause was found and a subtotal colectomy and Hartmann's procedure was performed. The patient had an uneventful postoperative course and was discharged on the 12th postoperative day with a temporary ileostomy.

In the pathology department, gross examination showed that the colon and especially the cecum was distended and its mucosal surface appeared flattened, with a polypoid lesion measuring $2.5 \mathrm{~cm}$ found in the cecum. Microscopic examination and immunohistochemical study of the polypoid lesion proved that it was a villoglandular adenoma with low-grade dysplasia, and full-thickness analysis of the resected colon revealed enlarged myenteric and submucosal neurons as well as an increased number of giant cells. The nerve bundles appeared hypertrophic, containing increased numbers of thickened disorganized axons. A small number of isolated ganglion cells and giant submucosal ganglia (containing 7-15 ganglion cells) (fig. 4) were also detected in the submucosa. Immunohistochemistry was applied by using antibodies against protein S-100, neuron-specific enolase, glial fibrillary acidic protein and synaptophysin. Protein S-100 and synaptophysin revealed an increase in 
Vougas et al.: Intestinal Neuronal Dysplasia Type B in Adults: A Controversial Entity

ganglion cells, and glial fibrillary acidic protein staining showed increased nerve plexus around blood vessels. The diagnosis of IND was established.

Three months later, during his second admission for restoration of bowel continuity, preoperative rectoscopy and rectal manometry showed no significant findings. During surgery for bowel continuity restoration, the upper third of the rectum was removed and an ileorectal (side to end) low anterior anastomosis to the posterior wall of the rectum $6 \mathrm{~cm}$ above the dentate line was performed. The patient was discharged on postoperative day 10 and during a 2-year follow-up has remained asymptomatic with normal bowel motility. The WCS score is 8 points, showing a significant difference compared to 20 points preoperatively.

\section{Discussion}

IND, Hirschsprung disease (HD), hypoganglionosis and ganglioneuromatosis constitute a group of malformations of the enteric nervous system called intestinal dysganglionosis [6]. Although these subtypes have distinct histological features, patients share a common clinical presentation characterized by intractable constipation and grossly delayed intestinal transit time [7]. Co-existence of HD with IND in a segment of the colon has been reported in 25$40 \%$ of cases and is suggested to be the cause of persistent constipation or postoperative enterocolitis recurrences after surgical treatment of $\operatorname{HD}[8,9]$.

IND can be divided into two distinct subtypes. IND type A, which comprises $5 \%$ of all cases and is characterized by congenital aplasia or hypoplasia of the sympathetic innervation, presents in the neonatal period, whereas IND type B, which comprises $95 \%$ of all cases of IND [4], is caused by malformation of the parasympathetic submucosal and myenteric plexus and is found in adults as well as in children [4].

IND is a distinct histopathologic and clinical entity [10], but there is mounting concern that IND type B is a clinical diagnosis only [11]. Gálvez et al. [12] suggested that enteric nervous system dysplasia, including histological features of neuronal intestinal dysplasia, could be induced by chronic intestinal obstruction. Additionally, no correlations of the clinical picture, radiological investigation and anorectal manometric studies with IND type B have been found so far [13].

The main diagnostic criteria for IND type B are hyperplasia of the submucosal plexus with the presence of giant ganglia, hyperganglionosis and increased acetylcholinesterase activity around submucosal vessels. Non-obligatory criteria include neural heterotopia and an increase in acetylcholinesterase activity in the lamina propria $[3,4,6,14]$. According to Meier-Ruge et al. [15] a diagnosis of IND type B can be made only if $15-20 \%$ of all ganglia in the submucosa of thirty serial sections are giant ganglia, with more than eight nerve cells. They also state that hyperplasia of the submucosal plexus and increased acetylcholinesterase activity in the nerve fibers of the lamina propria appear to be age-dependent, whereas the presence of giant ganglia is an age-independent factor of this disease. Thus, it has been proposed that the best indicator, but no specific of IND in adults, may be the presence of giant ganglia [16].

The pathophysiology of chronic constipation and colon dysmotility in IND is still not clear. It is known that 5-hydroxytryptamine is a polypeptide that stimulates contraction of smooth muscle layers and is produced by neuroendocrine cells. Kobayashi et al. [17] found an increase in neuroendocrine cells and morphological changes such as giant cells in patients with IND. A possible explanation of colon dysmotility in IND patients may be an increased number of 5-hydroxytryptamine-positive cells in the rectal mucosa, which could 
lead to chronic constipation [17]. Another interesting finding of this study is the correlation of the amount of neuroendocrine cells and the final therapeutic approach - conservative or surgery [17].

Conservative treatment of IND has been effective in 33-64\% of cases [18]. Nevertheless, other authors state that IND is a less mild disease than generally thought and have adopted a more aggressive surgical management of these patients [9]. Since colonic peristalsis is impaired by dysganglionosis, surgery is often the appropriate treatment [4]. Surgical treatment of IND type B does not have a unified concept as does HD [13]. An important issue in the surgical treatment of IND type B is to specify the colonic segment that has dysganglionosis and a demonstrable innervation defect. In cases of an isolated colonic segment affected by IND type B changes, it can be resected by the same techniques used for the treatment of HD [13]. The most common surgical techniques are the transabdominal procedures of Swenson, Rehbein, Duhamel and Soave [17, 19]. In cases of entire colon involvement and especially those with radiological evidence of megacolon and prolonged colonic transit time and IND type B changes, subtotal colectomy is the treatment of choice [4, 13].

In the present case, longstanding constipation could have resulted in IND-like colon changes or IND could have been the cause of chronic constipation. The patient presented with megacolon and received surgical treatment. A subtotal colectomy and ileorectal anastomosis in two stages with the anastomotic line $6 \mathrm{~cm}$ above the dentate line proved to be efficient within a follow-up period of more than 2 years. Full-thickness biopsy of the resected specimen and immunohistochemical study established the diagnosis of IND type B as there were giant ganglia, hyperganglionosis and increased acetylcholinesterase activity around submucosal vessels. Despite long-term attempts for conservative treatment and a sigmoidectomy in the meantime, subtotal colectomy with ileorectal anastomosis was the only successful therapeutic approach.

\section{Disclosure Statement}

The authors declare that they have no conflicts of interest.

\section{References}

1 Nezelof C, Guy-Grand D, Thomine E: Megacolon with hyperplasia of the myenteric plexua. An anatomoclinical entity, apropos of 3 cases. Presse Med 1970;78:1501-1506.

2 Meier-Ruge W: Über ein Erkrankungsbild des Colon mit Hirschsprung-Symptomatik. Verh Dtsch Ges Pathol 1971;55:506-510.

-3 Vijayaraghavan R, Chandrashekar R, Melkote Jyotiprakash A, Kumar R, Rashmi MV, Shanmukhappa Belagavi C: Intestinal neuronal dysplasia (type B) causing fatal small bowel ischaemia in an adult: a case report. Eur J Gastroenterol Hepatol 2006;18:773-776.

-4 Stoss F, Meier-Ruge W: Experience with neuronal intestinal dysplasia (NID) in adults. Eur J Pediatr Surg 1994;4:298-302.

5 Agachan F, Chen T, Pfeifer J, Reissman P, Wexner SD: A constipation scoring system to simplify evaluation and management of constipated patients. Dis Colon Rectum 1996;39:681-685.

6 Puri P, Rolle U: Variant Hirschsprung's disease. Semin Pediatr Surg 2004;13:293-299.

7 Montedonico S, Cáceres P, Muñoz N, Yáñez H, Ramírez R, Fadda B: Histochemical staining for intestinal dysganglionosis: over 30 years experience with more than 1,500 biopsies. Pediatr Surg Int 2011;27:479486.

8 Kobayashi H, Hirakawa H, Surana R, O’Briain DS, Puri P: Intestinal neuronal dysplasia is a possible cause of persistent bowel symptoms after pull-through operation for Hirschsprung's disease. J Pediatr Surg 1995;30: 253-257; discussion 257-259. 
Vougas et al.: Intestinal Neuronal Dysplasia Type B in Adults: A Controversial Entity

9 Mattioli G, Castagnetti M, Martucciello G, Jasonni V: Results of a mechanical Duhamel pull-through for the treatment of Hirschsprung's disease and intestinal neuronal dysplasia. J Pediatr Surg 2004;39:1349-1355.

10 Montedonico S, Acevedo S, Fadda B: Clinical aspect of intestinal neuronal dysplasia. J Pediatr Surg 2002;37: 1772-1774.

11 Lumb PD, Moore L: Back to the drawing board. Intestinal neuronal dysplasia type B: not a histological entity yet. Virchows Arch 1998;432:99-102.

12 Gálvez Y, Skába R, Vajtrová R, Frantlová A, Herget J: Evidence of secondary neuronal intestinal dysplasia in a rat model of chronic intestinal obstruction. J Invest Surg 2004;17:31-39.

13 Skába R, Frantlová M, Horák J: Intestinal neuronal dysplasia. Eur J Gastroenterol Hepatol 2006;18:699-701.

14 Kobayashi H, Hirakawa H, Puri P: What are the diagnostic criteria for intestinal neuronal dysplasia? Pediatr Surg Int 1995;10:459-464.

15 Meier-Ruge WA, Ammann K, Bruder E, Holschneider AM, Schärli AF, Schmittenbecher PP, Stoss F: Updated results on intestinal neuronal dysplasia (IND B). Eur J Pediatr Surg 2004;14:384-391.

-16 Ammann K, Stoss F, Meier-Ruge W: Intestinale neuronale Dysplasie des Erwachsenen als Ursache der chronischen Obstipation. Morphometrische Charakterisierung der Coloninnervation. Chirurg 1999;70:771776.

17 Kobayashi A, Yokota H, Kobayashi H, Yamataka A, Miyano T, Hayashida Y: Mucosal neuroendocrine cell abnormalities in patients with chronic constipation. Asian J Surg 2004;27:197-201.

18 Schmittenbecher PP, Glück M, Wiebecke B, Meier-Ruge W: Clinical long-term follow-up results in intestinal neuronal dysplasia (IND). Eur J Pediatr Surg 2000;10:17-22.

19 Chen Y, Nah SA, Laksmi NK, Ong CC, Chua JH, Jacobsen A, Low Y: Transanal endorectal pull-through versus transabdominal approach for Hirschsprung's disease: a systematic review and meta-analysis. J Pediatr Surg 2013;48:642-651.

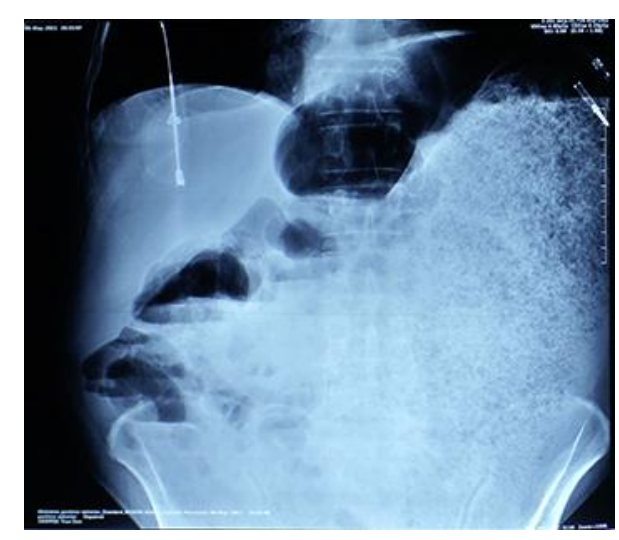

Fig. 1. Abdominal X-ray showing megacolon.

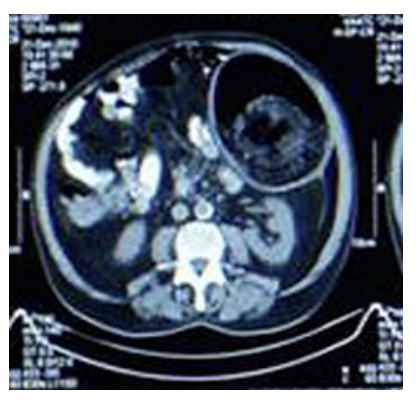

Fig. 2. Abdominal computed tomography scan showing excess bowel dilatation without obvious mechanical obstruction. 


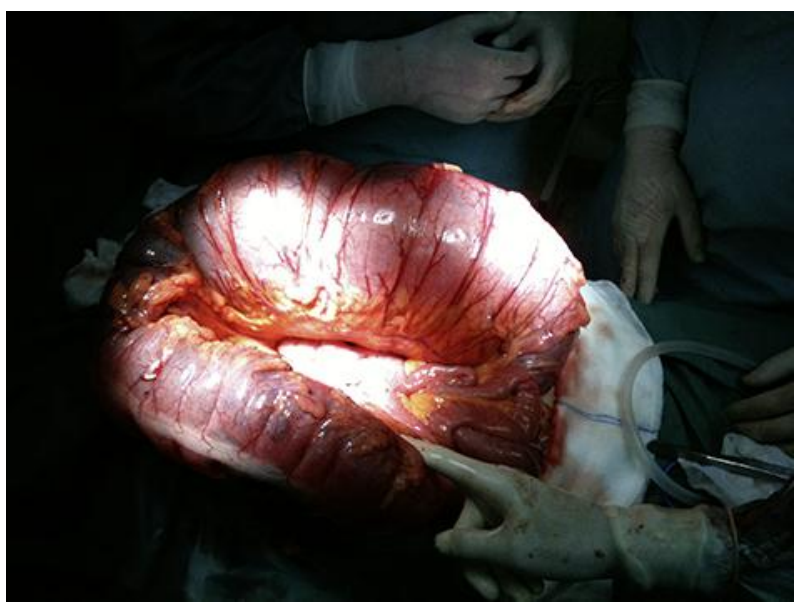

Fig. 3. Intraoperative picture of the dilated large bowel (after patient's personal permission).

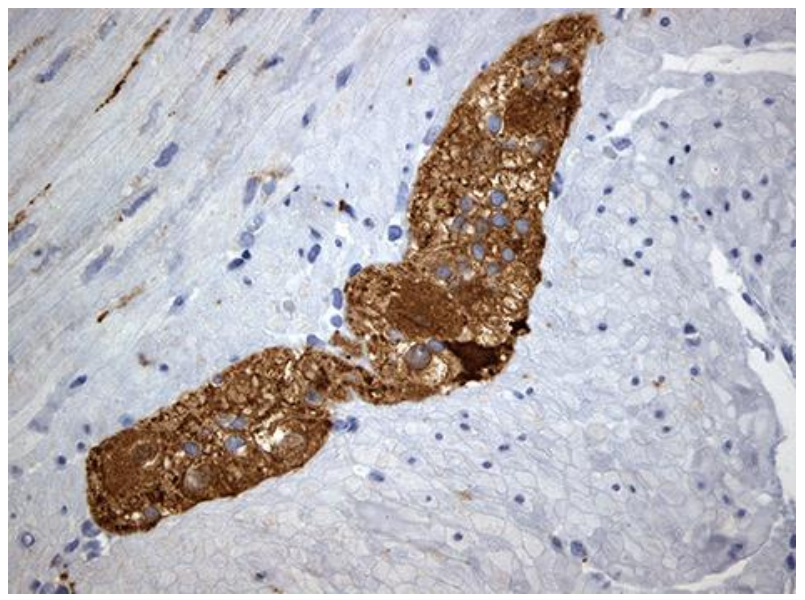

Fig. 4. Giant ganglion cells stained with neuron-specific enolase antibodies $(\times 400)$. 